\title{
Erweiterung des Treuhandpartnernetzes in Basel
}

Die meditax Fide Consult AG ist ein Tochterunternehmen der artax-Gruppe und engagiert sich speziell für die Bedürfnisse und Wünsche von Ärzten, Kliniken, Therapiezentren und medizinischen Institutionen. Die meditax Fide Consult AG ist mit ihrem hochqualifizierten Team von rund 25 Mitarbeitenden stets bestrebt, individuelle, kostenoptimierte Dienstleistungen in den Bereichen Treuhand, Finanz, Steuer- und Rechtsberatung und vielem mehr geschäftlich sowie auch privat anzubieten. Dr. iur. Bernhard Madörin, der CEO der meditax Fide Consult AG, verfügt über eine 25-jährige Erfahrung in der Treuhand- und Steuerberatung. Die artax-Gruppe ist in der Schweiz, in Deutschland und in Frankreich präsent und verfügt über internationale Kompetenz.

Unser Ziel ist, dafür zu sorgen, dass die Finanzen da bleiben, wo sie hingehören, und das ist bei Ihnen!

Ausschnitt des Dienstleistungsangebotes der meditax Fide Consult AG:

- Gründung und Aufbau einer medizinischen Institution;

- Finanzbuchhaltung und Jahresrechnungen;

- Betriebswirtschaftliche Analysen;

- Lohnbuchhaltung und Sozialabgaben;

- Revisionen und Wirtschaftsprüfung;

- Steuerberatung.

Die meditax Fide Consult AG hat ihren Hauptsitz in Basel. Die Büroräumlichkeiten befinden sich in der Nähe des Bahnhofs SBB mit gutem Zufahrtsweg sowie reservierten Parkplätzen für die Kunden.

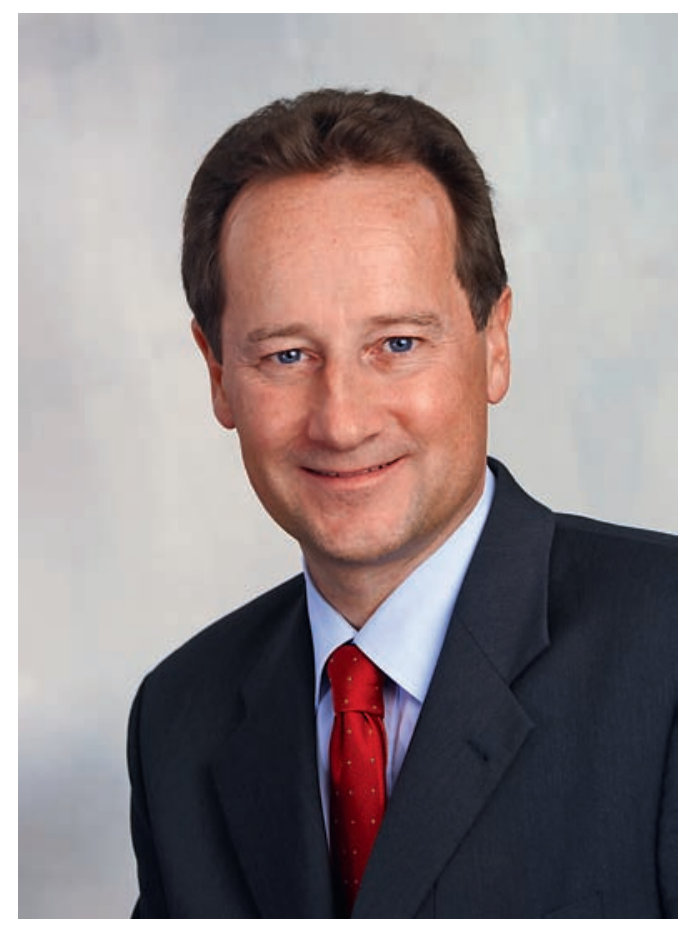

Auf die Kontaktnahme oder Ihren Anruf freut sich: meditax Fide Consult AG

FMH Treuhand Services

Dr. iur. Bernhard Madörin

Gartenstrasse 95

Postfach $\square 4002$ Basel

Tel. 0612256666 a Fax 0612256667

bernhard.madoerin@fmhtreuhand.ch

www.fmhtreuhand.ch
FMH TREUHAND SERVICES :

\section{Der Treuhänder weiss Rat!}

Sie suchen Unterstützung bei der Praxisgründung, -führung oder bei einer allfälligen Nachfolgeregelung?

Sei es bei der Ausarbeitung eines Businessplanes, der Buchführung, beim Jahresabschluss, den Steuern oder der Revision, unsere Treuhandspezialisten bieten Ihnen Lösungen nach Mass.
In allen drei Sprachregionen sind wir zu Hause und kennen die regionalen und branchenspezifischen Gesetzmässigkeiten ganz genau.

Vertrauen Sie unserem breit abgestützten Netzwerk an Spezialisten.

FMH Treuhand Services

FMH Consulting Services • Koordinationsstelle

Burghöhe $1 \bullet 6208$ Oberkirch

Telefon $0419250077 \bullet$ Fax 0419210586

mail@fmhtreuhand.ch $\bullet$ www.fmhtreuhand.ch 